\title{
(6) OPEN ACCESS \\ Season and region of birth as risk factors for coeliac disease a key to the aetiology?
}

\author{
Fredinah Namatovu, ${ }^{1}$ Marie Lindkvist, ${ }^{1}$ Cecilia Olsson, ${ }^{2}$ Anneli Ivarsson, ${ }^{1}$ \\ Olof Sandström ${ }^{1,3}$
}

${ }^{1}$ Department of Public Health and Clinical Medicine, Epidemiology and Global Health, Umeå University, Umeå, Sweden

${ }^{2}$ Department of Food and Nutrition, Umeå University, Umeå, Sweden

${ }^{3}$ Department of Clinical Sciences, Pediatrics, Umeå University, Umeå, Sweden

\section{Correspondence to} Fredinah Namatovu, Department of Public Health and Clinical Medicine, Epidemiology and Global Health, Umeå University, Umeå SE-901 87, Sweden; fredinah.namatovu@epiph. umu.se

Received 10 November 2015 Revised 14 June 2016 Accepted 26 June 2016 Published Online First 15 August 2016

\section{CrossMark}

To cite: Namatovu $F$, Lindkvist M, Olsson C, et al. Arch Dis Child

2016;101:1114-1118.

\section{ABSTRACT}

Background Coeliac disease (CD) incidence has increased in recent decades, characterised by variations according to sex, age at diagnosis, year of birth, month of birth and region of birth. Genetic susceptibility and exposure to gluten are the necessary factors in $C D$ aetiology, although several environmental factors are considered.

Methods A nationwide prospective cohort longitudinal study was conducted consisting of 1912204 children aged 0-14.9 years born in Sweden from 1991 to 2009. A total of 6569 children were diagnosed with biopsyverified CD from 47 paediatric departments. Using Cox regression, we examined the association between $C D$ diagnosis and season of birth, region of birth and year of birth.

Results Overall, CD risk was higher for children born during spring, summer and autumn as compared with children born during winter: adjusted HR for spring 1.08 (95\% Cl 1.01 to 1.16$)$, summer 1.10 (95\% Cl 1.03 to 1.18 ) and autumn 1.10 (95\% Cl 1.02 to 1.18$)$. Increased CD risk was highest if born in the south, followed by central Sweden when compared with children born in northern Sweden. Children diagnosed at $<2$ years had an increased CD risk if born in spring while those diagnosed at 2-14.9 years the risk was increased for summer and autumn births. The birth cohort of 1991-1996 had increased CD risk if born during spring, for the 1997-2002 birth cohort the risk increased for summer and autumn births, while for the birth cohort of 2003-2009 the risk was increased if born during autumn.

Conclusions Season of birth and region of birth are independently and jointly associated with increased risk of developing CD during the first 15 years of life. Seasonal variation in infectious load is the likely explanation.

\section{INTRODUCTION}

Coeliac disease (CD) is an immune-mediated enteropathy with a multifactorial aetiology. ${ }^{1}$ Only persons ingesting gluten and expressing human leucocyte antigen (HLA) DQ2 or DQ8 can develop CD. ${ }^{1}$ Apart from gluten other environmental factors have been suggested including: mode of delivery, infant feeding, gut microbiota, infections, socioeconomic status and season of birth, though evidence is contradictory. ${ }^{2-7}$ Several studies have shown that spring/summer birth is more common in patients with $\mathrm{CD}$ compared with their healthy counterparts $^{8-11}$ suggesting a role of seasonal exposures. A seasonal pattern has also been shown for type 1 diabetes, ${ }^{12}$ in children with a double

\section{What is already known on this topic?}

- Coeliac disease (CD) is increasing worldwide suggesting environmental factors in the aetiology.

- CD incidence varies with sex, age at diagnosis, year of birth, month of birth and by geographical location.

\section{What this study adds?}

- Spring births was associated with increased coeliac disease (CD) risk if diagnosed before 2 years of age while summer and autumn births were associated with high risk if diagnosed after 2 years of age.

- CD risk is higher in southern Sweden compared with the north with differences in seasonal incidence pattern.

- Seasonal viral infections during a vulnerable period of immune development are the likely explanation to observed seasonality but does not explain geographical differences.

diagnosis of $\mathrm{CD}$ and type 1 diabetes $^{6}$ and, in other immune-mediated diseases. ${ }^{13}$ Viral infections have a seasonal pattern and have also been associated with increased $\mathrm{CD}^{5-14}{ }^{15}$ and type 1 diabetes risk. ${ }^{16}$

In areas of high latitude such as Sweden, a seasonal pattern in exposure to sunlight and ultraviolet-B (UV-B) radiation is an exposure of interest. UV-B is needed for the synthesis of vitamin $\mathrm{D}$ in the skin yet in higher latitudes little vitamin $D$ is synthesised during winter thus populations depend on dietary vitamin $\mathrm{D}$ or supplementation. Vitamin D deficiency might be associated to seasonal variations in birth seen in autoimmune diseases including CD. It has also been suggested that vitamin D supplementation could contribute to increased CD risk. $^{17}$ Geographically, Sweden stretches about $1570 \mathrm{~km}$ from north to south, lying between latitudes $55^{\circ}$ and $69^{\circ}$ North. Southern Sweden is characterised by intense sunlight in spring and summer, while in northern Sweden spring is generally colder and summer is shorter. ${ }^{18}$

We have reported geographical variation in $\mathrm{CD}$ both in clinical and screening studies. ${ }^{19-21}$ Pronounced variations in $C D$ incidence was 
observed between birth cohorts during the CD epidemic (1985$1995)$ and postepidemic years, possibly related to variations in environmental exposures. ${ }^{22}$ The objective of this study was to explore the effects of season of birth on the risk of CD comparing different areas and time-periods in order to generate hypotheses about environmental factors associated with $\mathrm{CD}$ seasonality.

\section{METHODS}

The study used a prospective cohort longitudinal design with data obtained through the Swedish national registers, accessed through the Umeå SIMSAM Lab (SIMSAM: Swedish Initiative for Research on Microdata in the Medical and Social Sciences). ${ }^{23}$ Individual data obtained from Statistics Sweden and the Swedish National Childhood CD Incidence Register was linked using the Swedish personal identity number. ${ }^{24}$

The study consisted all children aged 0-14.9 years, born between 1991 and 2009. A total of 1912204 children were identified of which 6596 were diagnosed with CD, from 47 paediatric departments. CD diagnostic criteria were a small intestinal mucosa with villous atrophy, according to the 1990 European Society for Paediatric Gastroentology, Hepatology and Nutrition criteria. ${ }^{25}$

\section{Definition of explanatory variables}

Season of birth was classified according to four seasons: winter (December, January, February), spring (March, April, May), summer (June, July, August) and autumn (September, October, November). Region of birth was classified according to the Swedish national areas of the nomenclature of territorial units for statistics (NUTS 1), a geocode standard developed by the European Union for referencing administrative divisions of countries for statistical purposes. Age at diagnosis was defined as age when the first positive small intestinal biopsy was obtained and was estimated in years, divided into two categories: 0-1.9 (children <2 years) and 2-14.9 years (children between 2 and $<15$ years of age). Year of birth was categorised into four birth cohorts; the cohort of 1991-1996 represented children born during CD epidemic, 1997-2002 included children born immediately after the epidemic and 2003-2009 were born after the epidemic had abated.

\section{Statistical analysis}

Average CD incidence rates were calculated per month of birth and region of birth by dividing the number of cases diagnosed by the number of person years of follow-up, and reported per 100000 person years. Cox proportional hazard regression models were used to estimate the HR for CD diagnosis. For CD cases we considered age at diagnosis, while non-cases were considered censored at 15 years of age (the highest age included) or age at the end of the study follow-up (31 December 2009). The proportional hazards assumption for the independent variables was tested graphically with Kaplan-Meier curves. Bivariable (unadjusted) analyses were performed to explore the associations between $\mathrm{CD}$ and each of the explanatory variables. In the multivariable analysis (adjusted), each variable was adjusted for other studied factors. Both analyses were repeated while stratifying for age, region and birth cohort. Interaction was investigated for independent variables as cross terms pairwise in the adjusted model and checked for significance. Incidence rates were calculated using Microsoft Excel 2008 (V.12.3.2) and Cox proportional hazard was done using SPSS V.22.0 for Windows (SPSS, Chicago, Illinois, USA).

\section{Ethical considerations}

The Regional Ethical Vetting Board in Umeå approved research based on data obtained from the Umeå SIMSAM Lab.

\section{STUDY FINDINGS}

\section{Characteristics of the study population}

The total number of children, irrespective of their CD status is given in relation to season and region of birth and sex in table 1. The proportional hazards assumption was fulfilled for all studied variables and no significant interaction between independent variables and CD was found (results not shown). CD risk was higher for children born during spring, summer and autumn as compared with children born during winter. After adjusting for region of birth and sex, the effect of season of birth remained the same as observed in the unadjusted model,

Table 1 Descriptive results for the child population, the HRs show the relationship between the studied risk factors and coeliac disease risk for the period of 1991-2009

\begin{tabular}{|c|c|c|c|}
\hline \multirow[b]{2}{*}{ Risk factor } & \multicolumn{3}{|l|}{ All children } \\
\hline & Total N (\%) & $\begin{array}{l}\text { Bivariable }^{*} \\
\text { HR }(95 \% \mathrm{Cl}) \text {, p value }\end{array}$ & $\begin{array}{l}\text { Multivariablet } \\
\text { HR }(95 \% \mathrm{Cl}), \mathrm{p} \text { value }\end{array}$ \\
\hline \multicolumn{4}{|c|}{ Season of birth } \\
\hline Winter & 448979 (24) & 1.00 & 1.00 \\
\hline Spring & $520262(27)$ & 1.09 (1.01 to 1.16$), 0.02$ & 1.08 (1.01 to 1.16$), 0.02$ \\
\hline Summer & $500090(26)$ & 1.10 (1.02 to 1.18$), 0.01$ & 1.10 (1.03 to 1.18$), 0.01$ \\
\hline Autumn & $442863(23)$ & 1.09 (1.01 to 1.17$), 0.02$ & 1.10 (1.02 to 1.18$), 0.01$ \\
\hline \multicolumn{4}{|c|}{ Geographical regions } \\
\hline North & 330235 (17) & 1.00 & 1.00 \\
\hline Central & 746902 (39) & $1.19(1.10$ to 1.29$),<0.001$ & $1.19(1.10$ to 1.29$),<0.001$ \\
\hline South & $805315(42)$ & $1.59(1.48$ to 1.71$),<0.001$ & 1.59 (1.48 to 1.72$),<0.001$ \\
\hline \multicolumn{4}{|l|}{ Sex } \\
\hline Girls & $929492(49)$ & 1.00 & 1.00 \\
\hline Boys & $982702(51)$ & $1.83(1.74$ to 1.93$),<0.001$ & $1.83(1.74$ to 1.92$),<0.001$ \\
\hline
\end{tabular}




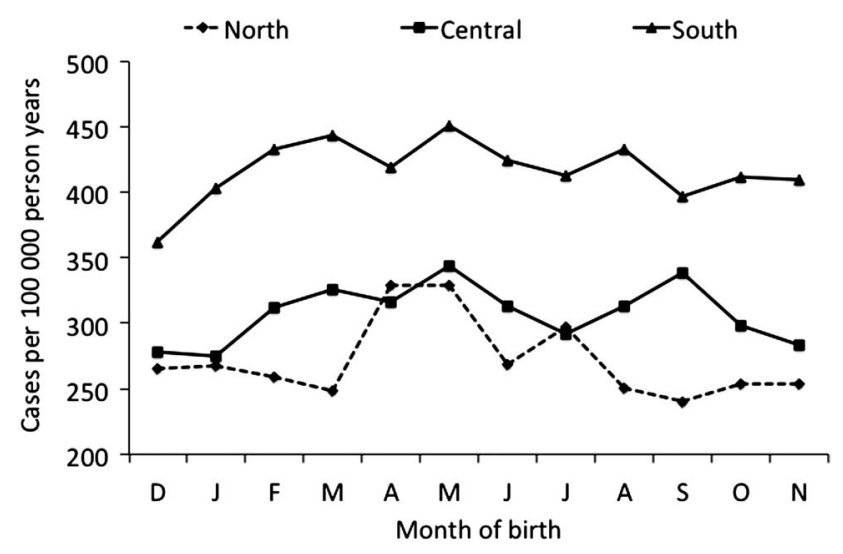

Figure 1 Coeliac disease incidence rate by month of birth in children aged 0-14.9 years during the period from 1991 to 2009 for the three nomenclature of territorial units for statistics (NUTS 1) regions in Sweden.

except for minor changes. In the unadjusted and the adjusted analyses, the risk of developing $\mathrm{CD}$ was lowest in northern region compared with southern and central Sweden. CD risk was more pronounced in girls in both unadjusted and adjusted analyses (table 1).

\section{CD incidence rate in relation to region and season of birth}

The incidence rate pattern for the NUTS regions differed by month of birth as shown in figure 1. In northern Sweden, the incidence rate was low throughout the year except for an increase in April and May. In central Sweden, an increase in CD incidence began in February to May. In the remaining months of June to November, the incidence rate appeared to drop aside from an increase in August. In southern Sweden, December to May were marked by a gradual increase, except for a decrease from June to November.

\section{CD risk in relation to region and season of birth stratified for age}

Among children below 2 years of age, CD risk was higher when born during spring compared with winter, no major differences were observed for other seasons, region of birth was not associated with CD risk (table 2). Children 2-14.9 years born during summer and autumn had an increased CD risk compared with those born during winter. This age group had the highest risk if born in southern Sweden, followed by central Sweden. This effect remained after adjusting for season and sex (table 2). CD risk was higher in girls than in boys regardless of age, although children aged 2-14.9 years had higher OR (table 2).

\section{CD risk in relation to region and season of birth stratified by birth cohort}

Among children born 1991-1996 the risk of developing CD was significantly increased if born during spring compared with winter. In the 1997-2002 birth cohort, CD risk was increased if born during summer and autumn. In the 2003-2009 cohort, CD risk was increased if born in autumn compared with winter (table 3). For children born between 1991 and 1996, the risk was increased for central and southern Sweden compared with northern Sweden. For children born in 1997-2002, increased CD risk was associated to being born in southern Sweden compared with the north, no association was observed for those born in central Sweden. Among children born between 2003 and 2009, the risk was increased for both central and south births compared with northern births (table 3). Girls had higher risk compared with boys in all years. The risk was highest among girls in the 2003-2009 birth cohort, followed by the birth cohort of 1997-2002 (table 3).

\section{DISCUSSION}

Spring birth was associated with increased CD risk in children diagnosed before 2 years of age while summer and autumn births were associated with high risk in children diagnosed after 2 years of age with noticeable changes over time. Seasonal pattern differed between regions, with increased CD incidence rates in southern Sweden from December to May. In central Sweden the increase started in February, while in north this started later and was more pronounced than in other regions. Stratification by age at diagnosis showed spring births to be associated with increased CD risk in children diagnosed before 2 years of age while summer and autumn births were associated with high $\mathrm{CD}$ risk in children diagnosed after 2 years.

One of the limitations of this study is lack of data on infections and vitamin D level, thus at the moment inference on how these might influence seasonality and subsequently CD risk remains speculative and calls for further investigation. CD risk may have been underestimated because CD cases without a PIN code were excluded. Lacking a PIN code was mainly due to not seeking parental consent, also a few declined to participate. Underestimation of CD risk is also possible since Marsh 3 was the standard for CD diagnosis; by implication potential cases, that is, with Marsh 1-2 or with elevated serological markers were excluded.

This is the first Swedish study investigating CD risk while taking into account four seasons and looking at geographical variations. The association between season of birth and CD has been the subject of several studies from Sweden. The first study followed children up to 1997 , and found summer to be associated with increased risk in children diagnosed before the age of 2 years. ${ }^{8}$ Lebwohl et al using Swedish pathology data showed a slightly increased risk in adults born during summer. ${ }^{9}$ Lewy et al reported increased CD risk in girls born during summer and in children diagnosed before 2 years of age but not in boys or in older children. ${ }^{10}$ A US study reported spring birth to be associated with increased CD risk in boys younger than 15 years of age at diagnosis. ${ }^{11}$ All evidence supports a seasonal environmental exposure in CD aetiology except for one Finnish study. $^{26}$

Children born in southern Sweden had the highest CD risk, followed by central and the lowest in northern Sweden. The Swedish population is considered genetically homogenous with $>50 \%$ prevalence of HLA risk genes. ${ }^{27}$ Consequently, geographical differences in CD risk are not fully explained by genetic clustering, suggesting the role of other environmental factors. Interestingly, CD is associated with acute viral infections like rotavirus, astrovirus and adenovirus and other viral infections. $^{5} 14 \quad 1528$ One hypothesis for increased CD risk and spring/summer birth is that, those infants are more likely to be weaned and introduced to gluten during autumn/winter, a time characterised by exposure to seasonal viral infections. Some studies suggested breast feeding to be protective against $\mathrm{CD}^{3}$ and there are several possible mechanisms for this including a modulatory effect on gut microbiota and its direct effect on the immune system. ${ }^{29}$ However, more recent studies could not confirm breast feeding's protective effect. ${ }^{40-33}$ Viral infections influence the intestinal microbiota, the barrier function and 
Table 2 The entire child population stratified in two age groups, the HRs show the relationship between the studied risk factors and coeliac disease risk for 1991-2009 period

\begin{tabular}{|c|c|c|c|c|}
\hline \multirow[b]{2}{*}{ Risk factors } & \multicolumn{2}{|l|}{ Age $<2$ years $(n=161140)$} & \multicolumn{2}{|l|}{ Age $>2$ years $(n=1751064)$} \\
\hline & $\begin{array}{l}\text { Bivariable } \\
\text { HR }(95 \% \mathrm{Cl}), \mathrm{p} \text { value }\end{array}$ & $\begin{array}{l}\text { Multivariable } \\
\text { HR }(95 \% \mathrm{CI}), \mathrm{p} \text { value }\end{array}$ & $\begin{array}{l}\text { Bivariable } \\
\text { HR }(95 \% \mathrm{CI}), \mathrm{p} \text { value }\end{array}$ & $\begin{array}{l}\text { Multivariable } \\
\text { HR }(95 \% \mathrm{Cl}), \mathrm{p} \text { value }\end{array}$ \\
\hline \multicolumn{5}{|c|}{ Season of birth } \\
\hline Winter & 1.00 & 1.00 & 1.00 & 1.00 \\
\hline Spring & 1.14 (1.00 to 1.29$), 0.05$ & 1.15 (1.02 to 1.31$), 0.03$ & 1.01 (0.93 to 1.09$), 0.83$ & 1.01 (0.93 to 1.09 ), 0.88 \\
\hline Summer & 1.04 (0.91 to 1.19$), 0.55$ & 1.05 (0.92 to 1.20$), 0.47$ & 1.14 (1.05 to 1.23$), 0.002$ & 1.14 (1.05 to 1.23$), 0.002$ \\
\hline Autumn & $0.91(0.79$ to 1.05$), 0.19$ & $0.92(0.79$ to 1.06$), 0.23$ & $1.11(1.02$ to 1.21$), 0.02$ & 1.12 (1.03 to 1.22$), 0.01$ \\
\hline \multicolumn{5}{|c|}{ Geographical regions } \\
\hline North & 1.00 & 1.00 & 1.00 & 1.00 \\
\hline Central & 1.12 (0.96 to 1.31$), 0.14$ & 1.14 (0.97 to 1.32$), 0.11$ & 1.11 (1.02 to 1.22$), 0.02$ & 1.11 (1.02 to 1.22$), 0.02$ \\
\hline South & 1.13 (0.97 to 1.31$), 0.11$ & 1.13 (0.98 to 1.32$), 0.10$ & $1.53(1.41$ to 1.67$),<0.001$ & 1.53 (1.41 to 1.67$),<0.001$ \\
\hline \multicolumn{5}{|l|}{ Sex } \\
\hline Boys & 1.00 & 1.00 & 1.00 & 1.00 \\
\hline Girls & 1.22 (1.10 to 1.34$),<0.001$ & 1.23 (1.11 to 1.35$),<0.001$ & $1.79(1.69$ to 1.90$),<0.001$ & 1.79 (1.69 to 1.89$),<0.001$ \\
\hline
\end{tabular}

Table 3 Results for the entire child population stratified by birth cohort, HRs show the adjusted association between the studied risk factors and coeliac disease risk for the period of 1991-2009

\begin{tabular}{|c|c|c|c|c|c|c|}
\hline \multirow[b]{2}{*}{ Risk factor } & \multicolumn{2}{|c|}{$1991-1996(n=666$ 178) } & \multicolumn{2}{|c|}{$1997-2002(n=529060)$} & \multicolumn{2}{|c|}{$2003-2009(n=716966)$} \\
\hline & HR $(95 \%$ Cl) & p Value & HR $(95 \% \mathrm{Cl})$ & $\mathrm{p}$ Value & HR $(95 \% \mathrm{Cl})$ & $p$ Value \\
\hline \multicolumn{7}{|c|}{ Season of birth } \\
\hline Winter & 1.00 & & 1.00 & & 1.00 & \\
\hline Spring & $1.12(1.00$ to 1.24$)$ & 0.04 & $1.01(0.90$ to 1.23$)$ & 0.47 & $1.05(0.90$ to 1.21$)$ & 0.55 \\
\hline Summer & 1.10 (0.98 to 1.22 ) & 0.09 & 1.14 (1.02 to 1.27$)$ & 0.02 & 1.14 (0.97 to 1.33$)$ & 0.11 \\
\hline Autumn & 1.04 (0.93 to 1.17 ) & 0.49 & 1.24 (1.10 to 1.39$)$ & $<0.001$ & 1.78 (1.64 to 1.92$)$ & 0.003 \\
\hline \multicolumn{7}{|c|}{ Geographical regions } \\
\hline North & 1.00 & & 1.00 & & 1.00 & \\
\hline Central & 1.19 (1.06 to 1.34$)$ & 0.004 & $1.06(0.94$ to 1.19$)$ & 0.36 & 1.28 (1.07 to 1.53$)$ & 0.008 \\
\hline South & 1.51 (1.35 to 1.68$)$ & $<0.001$ & $1.50(1.34$ to 1.69$)$ & $<0.001$ & 1.79 (1.51 to 2.14$)$ & $<0.001$ \\
\hline \multicolumn{7}{|c|}{ Sex } \\
\hline Boys & 1.00 & & 1.00 & & 1.00 & \\
\hline Girls & 1.73 (1.59 to 1.87$)$ & $<0.001$ & 1.78 (1.64 to 1.92$)$ & $<0.001$ & 2.11 (1.89 to 2.37 ) & $<0.001$ \\
\hline
\end{tabular}

Season of birth is grouped as follows: winter (December, January, February), spring (March, April, May), summer (June, July, August) and autumn (September, October, November). Region of birth is grouped according to the administrative division of nomenclature of territorial units for statistics (NUTS 1) regions.

increase mucosal permeability, which might be the mechanism of action in $\mathrm{CD}$ pathogenesis; however, this requires further investigation. $^{34}$

In the north, the high incidence period started later compared with the south and central parts of Sweden. Geographical difference in awareness is a possible explanation, though it cannot fully explain these variations since our previous screening studies reported a similar pattern between north and south as reported in this paper with a $1 / 3$ prescreening detection rate in all regions. ${ }^{20}$ Among Swedish physicians, it is known that the yearly epidemics of respiratory syncytial virus, rotavirus and influenza start in southern Sweden and spread northwards over a couple of months, ${ }^{35}$ which supports our findings. Moreover, there is a difference in distribution of rotavirus genotypes between Swedish regions. ${ }^{35}$

Another suggested mechanism for seasonal variation in CD risk is vitamin D deficiency due to differences in sunlight and UV-B exposure. ${ }^{36}$ Suboptimal levels of vitamin D during early childhood are a risk factor for immune-mediated diseases including multiple sclerosis, inflammatory bowel disease and type 1 diabetes mellitus. ${ }^{13} 37$ Sweden has large regional differences in sunlight and UV-B exposure, ${ }^{38}$ thus the low CD risk in the north does not support this hypothesis as this region receives few hours of sun exposure throughout the year. Moreover, in Sweden every child is recommended and offered government-funded vitamin D supplementation from 1 week to 2 years of age, ensuring adequate levels. A remaining possible link to sunlight and vitamin D is that pregnant women who give birth in spring have the lowest levels of vitamin D during late gestation when important programming and development of the fetal immune system takes place. ${ }^{39}$ Another hypothesis suggests increased $\mathrm{CD}$ risk due to high levels of vitamin $\mathrm{D}$; this fits the situation in south Sweden. ${ }^{17}$ This hypothesis is still new and is based on comparisons between countries. Tanpowpong and Camargo suggested a model where introduction of gluten, low levels of vitamin D and exposure to viral infections are 
responsible for the seasonal effect; ${ }^{36}$ whether this model is plausible remains to be confirmed.

\section{CONCLUSION}

We have confirmed a statistically significant effect of season of birth on the risk of being diagnosed with CD during childhood with the highest CD risk if born in south Sweden. Viral infections are the strongest possible risk factor in favour of our findings, although the role of vitamin $\mathrm{D}$ during pregnancy is still plausible. Whatever exposures are important in explaining seasonality, they have to work in a well-defined period, that is, during early life when the immune system is in an important developmental phase, otherwise there would be no seasonal pattern.

Acknowledgements The authors would like to thank Susanne Walther for her administrative support. The study was undertaken within the Centre for Global Health Research at Umeå University with support from the Swedish Council for Working Life and Social Research, FAS.

Contributors All authors contributed equally to the conceptualisation of the study, data collection, selection of the study variables, study design, interpretation of study findings and revision of the manuscript, and have approved the submitted versions of the manuscript. FN performed the statistical analyses and wrote the manuscript. $M L$ supervised the analysis, ensured quality of data and the study results. Al and OS provided clinical insights and interpretation of the study variables and findings.

Funding The study was funded by the Swedish Research Council, through the SIMSAM programme [839-2008-7491] and by the Swedish coeliac disease association, funders played no other role.

Competing interests None declared.

Ethics approval Swedish research ethical review board.

Provenance and peer review Not commissioned; externally peer reviewed.

Data sharing statement All data used were obtained from Sweden's national registers. These are open and data can be obtained upon request from Swedish data management agencies.

Open Access This is an Open Access article distributed in accordance with the Creative Commons Attribution Non Commercial (CC BY-NC 4.0) license, which permits others to distribute, remix, adapt, build upon this work non-commercially, and license their derivative works on different terms, provided the original work is properly cited and the use is non-commercial. See: http://creativecommons.org/ licenses/by-nc/4.0/

\section{REFERENCES}

1 Ludvigsson JF, Leffler DA, Bai JC, et al. The Oslo definitions for coeliac disease and related terms. Gut 2013;62:43-52.

2 Mårild K, Stephansson 0, Montgomery S, et al. Pregnancy outcome and risk of celiac disease in offspring: a nationwide case-control study. Gastroenterology 2012;142:39-45.

3 Akobeng AK, Ramanan AV, Buchan I, et al. Effect of breast feeding on risk of coeliac disease: a systematic review and meta-analysis of observational studies. Arch Dis Child 2006;91:39-43.

4 Szajewska H, Shamir R, Chmielewska A, et al. Systematic review with meta-analysis: early infant feeding and coeliac disease-update 2015. Aliment Pharmacol Ther 2015;41:1038-54.

5 Myléus A, Hernell O, Gothefors L, et al. Early infections are associated with increased risk for celiac disease: an incident case-referent study. BMC Pediatr 2012:12:194.

6 Adlercreutz EH, Wingren $\mathrm{CJ}$, Vincente RP, et al. Perinatal risk factors increase the risk of being affected by both type 1 diabetes and coeliac disease. Acta Paediatr 2015:104:178-84.

7 Olén $\mathrm{O}$, Bihagen $\mathrm{E}$, Rasmussen $\mathrm{F}$, et al. Socioeconomic position and education in patients with coeliac disease. Dig Liver Dis 2012;44:471-6.

8 Ivarsson A, Hernell O, Nyström L, et al. Children born in the summer have increased risk for coeliac disease. J Epidemiol Community Health 2003:57:36-9.

9 Lebwohl B, Green PH, Murray JA, et al. Season of birth in a nationwide cohort of coeliac disease patients. Arch Dis Child 2013;98:48-51.

10 Lewy $\mathrm{H}$, Meirson $\mathrm{H}$, Laron Z. Seasonality of birth month of children with celiac disease differs from that in the general population and between sexes and is linked to family history and environmental factors. J Pediatr Gastroenterol Nutr 2009:48:181-5

11 Tanpowpong $\mathrm{P}$, Obuch $\mathrm{JC}$, Jiang $\mathrm{H}$, et al. Multicenter study on season of birth and celiac disease: evidence for a new theoretical model of pathogenesis. J Pediatr 2013;162:501-4.

12 Kahn HS, Morgan TM, Case LD, et al. Association of type 1 diabetes with month of birth among U.S. youth: the SEARCH for diabetes in youth study. Diabetes Care 2009:32:2010-15.

13 Disanto G, Chaplin G, Morahan JM, et al. Month of birth, vitamin D and risk of immune-mediated disease: a case control study. BMC Med 2012;10:69.

14 Stene LC, Honeyman MC, Hoffenberg EJ, et al. Rotavirus infection frequency and risk of celiac disease autoimmunity in early childhood: a longitudinal study. Am J Gastroenterol 2006:101:2333-40.

15 Shulman LM, Hampe CS, Ben-Haroush A, et al. Antibodies to islet cell autoantigens, rotaviruses and/or enteroviruses in cord blood and healthy mothers in relation to the 2010-2011 winter viral seasons in Israel: a pilot study. Diabet Med 2014;31:681-5.

16 McKinney PA, Grp ESB. Seasonality of birth in patients with childhood Type I diabetes in 19 European regions. Diabetologia 2001;44(Suppl 3):B67-74.

17 Bittker $S$. Exposure to excessive oral vitamin $D$ in youth: a risk factor for celiac disease in later life? J Allergy and Asthma 2015;2. http://www.hoajonline.com/ journals/pdf/2054-9873-2-2.pdf

18 Odén A, Kanis JA, McCloskey EV, et al. The effect of latitude on the risk and seasonal variation in hip fracture in Sweden. J Bone Miner Res 2014;29:2217-23.

19 Olsson C, Stenlund H, Hörnell A, et al. Regional variation in celiac disease risk within Sweden revealed by the nationwide prospective incidence register. Acta Paediatr 2009;98:337-42.

20 Myléus A, Ivarsson A, Webb C, et al. Celiac disease revealed in 3\% of Swedish 12-year-olds born during an epidemic. J Pediatr Gastroenterol Nutr 2009;49:170-6.

21 Namatovu F, Strömgren M, Ivarsson A, et al. Neighborhood conditions and celiac disease risk among children in Sweden. Scand I Public Health 2014;42:572-80

22 Namatovu F, Sandström O, Olsson C, et al. Celiac disease risk varies between birth cohorts, generating hypotheses about causality: evidence from 36 years of population-based follow-up. BMC Gastroenterol 2014;14:59

23 Lindgren U, Nilsson K, de Luna X, et al. Data resource profile: Swedish microdata research from childhood into lifelong health and welfare (Umeå SIMSAM Lab). Int J Epidemiol 2016. http://ije.oxfordjournals.org/content/early/2016/05/10/ije.dyv358. short

24 Ivarsson $A$, Persson LÅ, Nyström L, et al. Epidemic of coeliac disease in Swedish children. Acta Paediatr 2000;89:165-71.

25 Walkersmith JA, Guandalini S, Schmitz J, et al. Revised criteria for diagnosis of coeliac disease. Report of working group of European society of paediatric gastroentology and nutrition. Arch Dis Child 1990;65:909-11.

26 Kokkonen J, Similä S, Vuolukka P. The incidence of coeliac disease and pyloric stenosis in children in Northern Finland. Ann Clin Res 1982;14:123-8.

27 Sandström 0, Rosén A, Lagerqvist $C$, et al. Transglutaminase IgA antibodies in a celiac disease mass screening and the role of HLA-DQ genotyping and endomysial antibodies in sequential testing. J Pediatr Gastroenterol Nutr 2013:57:472-6.

28 Troncone R, Auricchio $S$. Rotavirus and celiac disease: clues to the pathogenesis and perspectives on prevention. J Pediatr Gastroenterol Nutr 2007:44:527-8.

29 Andreas NJ, Kampmann B, Mehring Le-Doare K. Human breast milk: a review on its composition and bioactivity. Early Hum Dev 2015;91:629-35.

30 Aronsson CA, Lee HS, Liu E, et al. Age at gluten introduction and risk of celiac disease. Pediatrics 2015;135:239-45.

31 Lionetti E, Castellaneta S, Francavilla R, et al. Introduction of gluten, HLA status, and the risk of celiac disease in children. N Eng/ J Med 2014;371:1295-303.

32 Vriezinga SL, Auricchio R, Bravi E, et al. Randomized feeding intervention in infants at high risk for celiac disease. N Eng/ J Med 2014;371:1304-15.

33 Størdal K, White RA, Eggesbø M. Early feeding and risk of celiac disease in a prospective birth cohort. Pediatrics 2013;132:e1202-9.

34 Sanz Y, De Pama G, Laparra M. Unraveling the ties between celiac disease and intestinal microbiota. Int Rev Immunol 2011;30:207-18.

35 Rinder M, Tran AN, Bennet R, et al. Burden of severe rotavirus disease leading to hospitalization assessed in a prospective cohort study in Sweden. Scand I Infect Dis 2014;46:294-302.

36 Tanpowpong P, Camargo CA. Early-life vitamin D deficiency and childhood-onset coeliac disease. Public Health Nutr 2014;17:823-6.

37 Schwalfenberg GK. Solar radiation and vitamin D: mitigating environmental factors in autoimmune disease. J Environ Public Health 2012;2012:619381.

38 Klingberg E, Oleröd G, Konar J, et al. Seasonal variations in serum 25-hydroxy vitamin D levels in a Swedish cohort. Endocrine 2015;49:800-8.

39 Marques AH, O'Connor TG, Roth $\mathrm{C}$, et al. The influence of maternal prenatal and early childhood nutrition and maternal prenatal stress on offspring immune system development and neurodevelopmental disorders. Front Neurosci 2013;7:120. 